\title{
VARIEDADES DO ENATIVISMO: PROPOSTAS RADICAIS E COGNIÇÃO SUPERIOR
}

\author{
Jeferson Diello Huffermann ${ }^{1}$
}

\begin{abstract}
RESUMO
Desde os anos noventa do século XX um programa de pesquisa interdisciplinar que transpassa a filosofia, a psicologia cognitiva, a inteligência artificial, robótica corporificada e a linguística vem ganhado espaço sob a alcunha de Enativismo (Enactvism). Apresentar e contextualizar abordagens enativistas mais radicais à cognição superior é o objetivo do presente texto. Uma motivação significativa para uma atitude positiva ao enativismo é o sucesso de explicações do fenômeno perceptual da visão que enfatizam o caráter ativo da percepção. A partir de uma certa leitura enativista pode-se defender que a percepção visual é um tipo de cognição básica (não-representacional), que pode ser explicada de modo relacional, a partir das habilidades do agente cognitivo engajado em um determinado ambiente e suas características. De modo que a percepção é deveras aproximada, senão identificada, com um saber-fazer. Um panorama do enativismo e suas variedades é traçado de modo a entender as perspectivas anti-representacionalistas; com isso é possível abordar o tratamento dado, de uma perspectiva radical, aos contextos que a princípio demandam apelo à noção de representação em sua explicação (contextos do que se pode chamar cognição superior). As variedades são o autointitulado enativismo radical (REC), o enativismo autopoiético e o enativismo sensório-motor. Após a exposição, encerra-se discutindo alguns problemas e possibilidades de avanço da agenda radical à explicação da cognição superior.
\end{abstract}

Palavras-chave: Filosofia das Ciências Cognitivas. Enativismo Autopoiético. Enativismo Sensório-Motor. Enativismo Radical. Cognição Superior.

\footnotetext{
ABSTRACT

Since the 90th decade of the 20th century an interdisciplinary research program the trespass the areas of Philosophy, Cognitive Psychology, Artificial Intelligence, Embodied Robotics and Linguistics has carving up space under the name Enactivism. Show and contextualize the more radical enactive approaches to high cognition is our goal in this paper. A significant motivation to have a positive attitude towards enactivism is its success in explanations of vision that emphasize the active character of perception. For a certain enactivist reading visual perception is a kind of basic (non-representational)

${ }^{1}$ Doutorando do PPGFIL UFRGS. Bolsista CAPES.

E-mail: jeferson.diello@gmail.com.
} 
cognition that can be explained in a relational manner, through the skills of the cognitive agent engage in a determined environment and its characteristics. Follows that the perception is similar to, if not identified as, know-how. An overview of the varieties of enactivism is traced, with the goal of understanding the anti-representational perspectives; with that is possible to approach treatment, from a radical perspective, to the contexts that at first glance demand the notion of representation in its explanation (contexts of what could be call higher cognition). The varieties are the radical enactivism (REC), the autpoietic enactivism and the sensorimotor enactivism. After the exposition, we discuss some problems and possibilities of progress of the radical explanation of higher cognition.

Keywords: Philosophy of Cognitive Sciences. Autopoietic Enactivism. Sensorimotor Enactivism. Radical Enactivism. Higher Cognition.

\section{Considerações Iniciais}

O enativismo pode ser caracterizado como parte de um programa de pesquisa interdisciplinar que transpassa a filosofia, a neurociência, a antropologia cognitiva, a psicologia cognitiva, a inteligência artificial, a robótica corporificada e a linguística. Trata-se de um cada vez mais prolífico e diverso grupo de estratégias de pesquisa no campo das ciências cognitivas. Características comuns entre posições enativistas incluem sua oposição ao cognitivismo clássico ${ }^{2}$ ou modelo computacional (representacionalista) da cognição, optando pela centralidade da ação na explicação do processo cognitivo. Cognição é algo dependente das ações do organismo em seu ambiente imediato, e não pode ser propriamente entendida ao se ignorar como as características do ambiente balizam o agregado de possibilidades de ação do organismo e em como as ações elas mesmas afetam o ambiente. Ao se afastar ou desenfatizar a noção de representação, diferentes instrumentais conceituais são empregados - ênfase em habilidades sensório-motoras, conceitos biológicos como o conceito de autopoiesis (uma forma de autono-

\footnotetext{
${ }^{2} \mathrm{O}$ cognitivismo clássico não será tematizado ou tratado neste texto. Trata-se da perspectiva que defende que a mente se localiza principalmente no cérebro ou no sistema nervoso central e que se apoia fortemente na analogia entre a mente e o software de um computador; entende-se a partir do cognitivismo clássico que os seres humanos são como que "computadores de carne". Desse modo em geral assume-se uma distinção clara entre sensação (input), cognição (processing) e ação (output). Maiores detalhes acerca dessa perspectiva sobre cognição podem ser encontrados nos verbetes da Stanford Enciclopedia of Philosophy sobre o modelo computacional da mente $<$ https://plato.stanford.edu/entries/computationalmind/> e sobre Ciências Cognitivas < https://plato.stanford.edu/entries/cognitive-science/ \#CogSci>.
} 
mia característica dos seres vivos), a psicologia ecológica gibsoniana (principalmente a teoria das affordances), assim como conceitos da fenomenologia. Complementarmente e de modo não surpreendente, também são incorporados diversos resultados empíricos. Propostas enativistas bem-sucedidas mostram como é possível entender diferentes fenômenos perceptuais de modo a reduzir ou até mesmo eliminar o papel da noção de representação na compreensão dos mesmos. Um dos exemplos mais famosos e influentes de fenômeno perceptual compreendido à maneira enativista é o tratamento de Alva Noë (2004 \& 2012) à visão de modo a enfatizar o uso de habilidades sensório-motoras na interação com aquilo que é visto. Gibson ([2015] 1979), também trata da visão de modo similarmente não-representacionalista, tratando-se de um antecedente importante. A experiência visual tem sido explicada de maneira frutífera em termos enativistas, sendo essa explicação bem-sucedida uma das motivações à transposição de estratégias enativas a outros casos de cognição. Subsequentemente, estratégias enativas vêm sendo empregadas para dar conta de outros tipos de cognição fortemente associadas às noções de conteúdo mental e estados internos. Ditas radicais, essas estratégias acarretam a rejeição da tese de que toda cognição consiste na articulação ou manipulação de conteúdos representacionais.

$\mathrm{Na}$ literatura é possível encontrar tanto propostas que buscam eliminar quase que completamente a noção de representação do aparato explicativo de processos cognitivos entendidos como casos paradigmáticos de estados representacionais quanto propostas que visam explicar como cognições representacionais podem ser incorporadas numa teoria enativisa radical como emergentes da cognição básica. No primeiro caso, o estudo de cada tipo de cognição revelaria que os contextos que aparentemente demandam representações como recursos explicativos de fato podem ser compreendidos sem o emprego dessa noção. Como consequência, dever-se-ia a partir dessa estratégia se adotar uma posição fortemente anti-intelectualista, segundo a qual toda cognição (o que incluiria conhecimento proposicional) se reduziria ao exercício de habilidades sensório-motoras e acoplamento com o ambiente - uma posição que pode soar a muitos extremamente contraintuitiva e revisionista. Tal consequência pode ser evitada através da adoção de uma perspectiva metodológica a partir da qual se deve explicar a cognição 
de modo anti-intelectualista o tanto quanto possível, deixando em aberto se a noção de representação é, em princípio, completamente eliminável. Propostas desse tipo seriam abordagens radicais metodológicas, evita-se o jargão representacionalista o máximo possível, dando ênfase à dimensão corporificada da cognição e a relação do agente cognitivo com seu meio. Já no segundo caso, busca-se estabelecer uma unidade explicativa entre cognição básica e superior. Visa-se explicar como cognição dotada de conteúdo (nesse sentido representacional) emerge a partir de atividades socioculturais. Entendendo, desse modo, a cognição humana como um sistema dinâmico em que conteúdo intencional é uma propriedade emergente. Adotando-se um naturalismo não-redutivo, um naturalismo metodológico ${ }^{3}$, é possível dar encaminhamentos para a articulação da resposta às perguntas mais propriamente empíricas acerca de tal sistema dinâmico. Apesar de empiricamente bem informada, essa segunda estratégia radicalizada com relação à cognição superior é uma abordagem filosófica, portanto, engajada principalmente com a tarefa de aclaramento conceitual. Para os propósitos do ensaio, avalia-se em detalhe somente a segunda estratégia, em específico o enativismo autoproclamado radical.

O Enativismo Cognitivo Radical, ou REC na abreviatura em inglês cunhada por Daniel Hutto e colaboradores (Hutto, 2017; Hutto \& Satne, 2015; Hutto \& Myin, 2013 \& 2017) é uma tentativa de unificação de estratégias enativistas de modo a rejeitar a ubiquidade de representações na cognição. Rejeitar a ubiquidade de conteúdos representacionais no processo cognitivo, por sua vez, faz com que o papel explicativo de tais conteúdos tenha que ser revisto. Independentemente da abordagem, qualquer enativista que nega a ubiquidade das representações nos processos cognitivos deparase com o problema de explicar aqueles estados cognitivos que a princípio demandam a noção de representação para sua compreensão adequada, processos cognitivos orientados a algo ausente ou não atual. As cognições em questão são aquelas que podem ser agrupadas sob o termo cognição superior

\footnotetext{
${ }^{3}$ Por oposição a propostas naturalistas que visam reduzir os fenômenos cognitivos a um subconjunto de fenômenos que ocorrem no âmbito do sistema nervoso central. Características comuns a esse tipo reducionista de naturalismo são a eliminação do vocabulário intencional e o cerebrismo (a tese de que a cognição é corretamente localizada no cérebro ao no sistema nervoso central). Para uma abordagem desse tipo ver Dennett (1991).
} 
(memória imagética, planejamento de atividades futuras, inferências preditivas, pensamento abstrato, linguagem proposicional etc).

Contudo, primeiramente, uma observação sobre a noção de cognição superior é importante. Não há distinção nítida no enativismo entre percepção e faculdades que possivelmente são mais associadas ao termo cognição, como, por exemplo, juízo e reflexão, pois tais processos cognitivos são, em última instância, atividades que podem ser informadas por processos básicos como a percepção visual. Em outras palavras, deve-se ter cautela no uso de metáforas hierárquicas e modulares para descrever processos cognitivos. Utiliza-se essa distinção entre cognição básica e superior pré-teoricamente, isto é, sem ainda qualquer comprometimento com uma definição de "cognição”. Basta-se aceitar casos paradigmáticos de cognição básica (percepção) e de cognição superior (raciocínio reflexivo). Os processos superiores e os processos básicos podem influenciar uns aos outros. Uma das características do modelo computacional da mente é negar a influência de processos ditos superiores nos processos ditos básicos, sendo literalmente hierárquica e modular. Na perspectiva enativista, há um comprometimento com a ideia de uma interação causal contínua entre agente cognitivo (e todas as suas modalidades de cognição) e o ambiente - também chamada de acoplamento. As divergências surgem a partir de caracterizações mais precisas dessa interação, e, novamente, o ponto em comum de perspectivas consideradas radicais ou anti-representacionalistas é a rejeição de que essa interação é necessariamente mediada por representações.

\section{Variedades do Enativismo}

Abordagens de enativistas às ciências cognitivas almejam explicar processos cognitivos humanos em geral de modo a enfatizar a ação humana e diminuir radicalmente (quando não eliminar) o apelo a estados internos ou dotados de conteúdo representacional. A iniciativa tem uma história relativamente recente de menos de 30 anos, porém, como já mencionado, com antecedentes na filosofia de Merleau-Ponty e na psicologia ecológica de Gibson. Francisco Varela, Evan Thompson e Eleanor Rosch ao publicarem em 1991 The Embodied Mind: Cognitive Science and Human Experience (TEM), no 
qual empregam conceitos da fenomenologia, das ciências cognitivas, da psicologia e do budismo para articular um novo programa de pesquisa com ênfase no aspecto ativo e corporificado da cognição, tornam-se os precursores da abordagem enativista. A partir dessa obra a visão da cognição como algo ativo e corporificado adquire credibilidade e vem sendo consolidada a partir de novos trabalhos. Em TEM, caracterizam inicialmente a perspectiva enativa como consistindo de duas teses principais "(1) percepção consiste em ação guiada perceptualmente e (2) estruturas cognitivas emergem a partir de padrões sensório-motores recorrentes que permitem a ação ser perceptualmente guiada" (TEM, 1991, p. 173)4 É possível entender as variedades de enativismo como variedades de estratégias relacionadas a (1) e (2). Desde a publicação de TEM, identificam-se pelo menos três correntes mais ou menos distintas de enativismo: autopoiético, sensório-motor e radical. Classificadas desse modo por Silverman e Vilalobos (2017), as correntes dialogam entre si de modo a terem uma intersecção substancial. $\mathrm{O}$ enativismo autopoiético, que se poderia dizer explora em maior grau (2), enfatiza o aspecto biológico e dinâmico da estrutura cognitiva orientada à ação. $\mathrm{O}$ enativismo sensório-motor, que se poderia dizer explora em maior grau (1), caracteriza o conteúdo e a característica central da percepção em termos da relação entre experiência e atividades corporificadas (exercer habilidades sensóriomotoras). Por último, REC, cujo enfoque é a rejeição ao representacionalismo em explicações dos processos cognitivos básicas em favor de estratégias focadas nas interações do agente cognitivo com o ambiente, para a partir dos processos básicos explicar como surge a cognição com conteúdo. A abordagem radical propõe-se uma unificação do enativismo tendo em vista seu inimigo comum, o representacionalismo. Por consequência, ao explorá-la em detalhes ambas as abordagens autopoiética e sensório-motora podem ser contempladas.

\footnotetext{
4 “(1) perception consists in perceptually guided action and (2) cognitive structures emerge from the recurrent sensorimotor patterns that allow action to be perceptually guided." Francisco Varela, Evan Thompson e Eleanor Rosch, The Embodied Mind: Cognitive Science and Human Experience, 1991, p. 173. Tradução minha.
} 


\subsection{Enativismo Autopoiético}

Em linhas muito gerais, os enativistas agrupados sob o rótulo autopoiético tem em comum sua ênfase na autonomia sui generis e especialmente dinâmica dos organismos vivos na caracterização de cognição. O exemplo clássico de autopoiesis é o da bactéria unicelular. A bactéria é separada do restante do ambiente por uma membrana semipermeável que é criada e mantida por uma rede de processos metabólicos, tais quais absorção de nutrientes e expulsão de resíduos, que se entrecruzam nas fronteiras da bactéria. A mesma é um sistema autopoiético - um sistema que gera e mantém sua organização através de suas operações, um sistema produtor de si mesmo ${ }^{5}$. As especificidades dessas interações entre organismo e ambiente são relevantes porque as estruturas corporificadas no organismo e as propriedades do ambiente importam para compreender seu desenvolvimento, de modo que podemos entender as estruturas como direcionadas ao ambiente. No caso da bactéria, sacarose somente assume o estatuto de alimento quando em relação ao organismo. A interação entre a bactéria e a molécula de sacarose é uma interação direcionada pelas necessidades e capacidades metabólicas da bactéria. As necessidades e capacidades metabólicas, por sua vez, desenvolveram-se a partir das habilidades herdadas e adquiridas. Ser um sistema autopoiético explica as interações especificadas ou significativas dos organismos, e a cognição passa a ser entendida como uma série de interações significativas, orientadas a exercer uma atividade. Um conceito chave dessa proposta enativa é o conceito de sense-making ou busca por sentido. A busca por sentido contemporaneamente é entendida como "a capacidade de um sistema autônomo regular adaptativamente suas operações e suas relações com o ambiente dependendo das consequências virtuais para sua própria viabilidade enquanto forma de vida." ${ }^{\prime 6}$ Enativistas autopoiéticos defendem que interações sensório-motoras simples entre organismo e ambiente (suas operações e relações) contém uma forma de direção ou orientação teleológica em relação ao ambiente - as ações da bactéria se direcionam ao ambiente

\footnotetext{
5 (Cf. Maturana \& Varela, 1980, p. 79)

6 " $[\mathrm{T}]$ he capacity of an autonomous system to adaptively regulate its operation and its relation to the environment depending on the virtual consequences for its own viability as a form of life." Ezequiel A. Di Paolo, Elena Clare Cuffari, e Hanne De Jaegher Linguistic Bodies: the continuity between life and language, 2018, pp. 34. Tradução minha.
} 
rico em sacarose em virtude da organização dinâmica das estruturas organizacionais distintivas da bactéria. A bactéria unicelular já exibe algo que podemos denominar comportamento, ela tem estruturas que detectam ambientes potencialmente ricos em sacarose e estruturas reativas que fazem com que ela se mova ao ambiente possivelmente rico em alimento. Formase já nesses organismos um padrão sensório-motor, um padrão entre o que o organismo "sente" e como se move. Nos organismos em geral há a necessidade de coordenação entre o que o organismo identifica no seu ambiente imediato (características físicas, químicas, sociais) e certa reatividade (a produção de certo elemento químico, mudança no padrão de movimento, ação de acordo com certa norma social). O caso de organismo multicelulares com vidas caracterizadas por movimento constante em pelo menos em um estágio de sua existência, o que inclui o nosso caso, demanda estruturas de organização muito mais sofisticadas. Diferentes estruturas organizacionais orientadas a diferentes atividades específicas são diferentes formas de cognição. Dada a relação estruturada e estruturante dos seres humanos com seu ambiente, ele é capaz de ver e refletir. Desse modo, trata-se a base para a cognição como o próprio dinamismo daquilo que é vivo, comprometendo-se com uma forte continuidade entre "vida" e "mente". A autonomia característica do que é vivo é o ponto de partida para uma explicação da cognição. Uma certa compreensão da cognição que iguala vida e cognição - como processo dos seres vivos em geral, análogo ao metabolismo e a reprodução não decorre necessariamente dessa tese. Há enativistas dessa linha que colapsam vida e cognição (Maturana \& Varela, 1980) e aqueles que partem da noção de autopoieses como condição necessária, ainda que não suficiente para cognição (Di Paolo, Cuffari, e De Jaegher, 2018)7.

A atividade da bactéria acima ser tratada como cognitiva ou quasecognitiva ainda deixa em aberto como essa atividade se relaciona com a percepção humana ou inferências preditivas. É proposta uma continuidade evolutiva entre os processos e estruturas dos organismos mais simples e os seres humanos, mas os pormenores variam de acordo com teses adicionais. A

\footnotetext{
${ }^{7}$ Para esses autores, além da autopoiesis, o organismo que é um sistema cognitivo deve poder ser considerado um agente e, portanto, não ser meramente reativo ao ambiente. Encontra-se em Huffermann e Noguez (2020) uma caraterização detalhada da posição de Di Paolo, Cuffari, e De Jaegher (2018)
} 
ideia é que a cognição humana tem como base a interação com o ambiente típica dos seres vivos, portanto, sem atenção aos mecanismos biológicos a cognição torna-se ininteligível. Porém, a centralidade da noção de autopoiesis e seu papel na explicação da cognição envolve certa confusão. A partir da constituição de um sistema autopoiético poderá emergir também o equivalente enativista à "perspectiva individual" da qual descrições fenomenológicas e linguagem intencional são objeto no caso humano? Podemos já nesse nível falar de algo análogo a subjetividade e intencionalidade ${ }^{8}$ humana? Concomitantemente à manutenção do seu status de vivo, os organismos ao interagirem com o ambiente adquirem novas unidades estruturais, e consequentemente, novas formas de ação específica no ambiente. Eles adquirem um nível maior de vida (autopoiesis)? Nós somos mais vivos que bactérias? A noção não é útil ou compreensível em termos de graus, o que dificulta a proposta. Di Paolo e colaboradoras (2018), assumindo a continuidade entre vida e cognição, enriquecem seu enativismo com seu próprio ferramental conceitual: agência, adaptatividade, busca por sentido participatória. Hutto, a partir de REC, sugere deflacionar as afirmações do enativismo autopoiético (AE):

Talvez a maior conquista de AE tenha sido prover uma maneira de pensar sobre a orientação da cognição de agentes em termos de normas biológicas, sem invocar quaisquer padrões que cognitivistas insistem requeridos para dar sentido a esse fenômeno (e.g. conteúdos mentais, intenções anteriores, direções de encaixe [fit], e assim por diante). ${ }^{9}$

A noção importante é de autonomia de sistemas autopoéticos e como ela nos permite dar sentido preciso a uma normatividade biológica. Principalmente ao ser conjugada com o conceitual da teoria dos sistemas dinâmi$\cos ^{10}$, pois captura o relevante dessa interação entre organismo e ambiente. Os organismos vivos, unicelulares e multicelulares constantemente mantêm sua unidade estrutural através de uma série de processos, constantemente al-

\footnotetext{
${ }^{8}$ Discorro acerca do conceito de intencionalidade ao discutir a proposta de Hutto e colaboradores de uma intencionalidade primitiva.

9 "Perhaps AE's great achievement has been to provide a way of thinking about the basic goal-directed cognition of agents in terms of biological norms without invoking any of the standard equipment that cognitivists insist is required for making sense of that phenomenon (e.g. mental contents, prior intentions, directions of fit, and so on)." Daniel D. Hutto, "REC: Revolution Effect by Clarification”, 2017, p.379. Tradução minha.

${ }^{10}$ Usar o ferramental dos sistemas dinâmicos para compreender a cognição não é exclusividade do enativismo, o conceito de afforndandes da psicologia ecológica é as vezes tratado dessa maneira (Cf. Turvey et all, 1981)
} 
terando as "fronteiras" entre organismo e meio. Essa unidade estrutural se dá ao longo tempo e é dinâmica, constantemente estabelecida e reestabelecida, podendo desse modo ser compreendida pelo instrumental matemático da teoria dos sistemas dinâmicos. A emergência de novas propriedades é uma característica dos sistemas dinâmicos. O organismo vivo é um sistema dinâmico permanentemente envolto em atividades diferenciadas pela ação específica (cognitiva) direcionada a esse ambiente. Em outras palavras "Para a abordagem enativa, cognição é ação corporificada. Em um sentido concreto e prático, um sistema cognitivo é corporificado na medida em que sua atividade depende de maneira não trivial do corpo." ${ }^{11}$

A emergência de um sistema cognitivo é o surgimento de um sistema a partir da geração e sustentação ativa da própria identidade por um acoplamento dinâmico com o ambiente. A partir dessa perspectiva, fica imposta a tarefa de descrever e explicar: como a cognição (incluído a cognição superior) emerge de uma série interações; que estruturas organizacionais direcionam as interações; como enquadrar (se é necessário enquadrar) a noção de representação nesse esquema; etc. Uma das propostas de acoplamento dinâmico ou coordenação dinâmica entre agente cognitivo e ambiente, de responder como o corpo animado inserido no mundo pode ser uma mente (cognitivo), é a partir das propostas que enfatizam as habilidades sensóriomotoras.

\subsection{Enativismo Sensório-motor}

Voltando ao item (1) de TEM já mencionado: como a percepção pode ser ação perceptualmente guiada? Uma maneira seria recorrendo a contingências sensório-motoras: padrões recorrentes de dependência e invariância entre percepção e ação. Hurley $(2001)^{12}$, por exemplo, propõe o loop ação-percepção-ação entre o organismo e o ambiente imediato como central para entender a percepção. Contingências sensório-motoras seriam as maneiras legiformes (de acordo com leis) nas quais o estímulo sensório-motor

\footnotetext{
11 "For the enactive approach, cognition is embodied action. In a concrete and practical sense, a cognitive system is embodied to the extent to which its activity depends non-trivially on the body". Hanne De Jaegher e Ezequiel Di Paolo "Participatory sense-making: An enactive approach to social cognition” 2007, p. 487-488. Tradução minha.

12 Proposta que influencia diretamente O'regan \& Noë (2001)
} 
muda de acordo com como organismo se move e altera o ambiente. $\mathrm{O}$ exemplo a seguir da percepção de um prato como objeto redondo é um exemplo que se vale dessa noção. A razoabilidade do enativismo sensório-motor pode ser compreendida ao se refletir sobre como os aparentes limites da percepção visual humana são superados por nossas capacidades de movimento e alteração do ambiente. Como, apesar do fato de que somente temos informação visual de partes (ou perspectivas) dos objetos a cada instante no tempo vemos os objetos na sua totalidade e de forma contínua? É esse tipo de questão que o enativismo sensório-motor procura responder.

Para a resposta enativista sensório-motor considere a seguinte explicação: quando olho para um prato em cima de uma mesa, ele parece oval ou oblongo dependendo da minha perspectiva, mas eu também o vejo como redondo. Vejo o prato como redondo porque sou capaz, ao mover-me pelo ambiente, de manipular o arranjo óptico de modo a estabelecer que seu formato redondo é uma informação invariante. Não apenas a informação invariante, o formato e o tamanho do prato são vistos, mas também a sua aparência, as qualidades relacionais que obtêm apenas com respeito à minha localização. Vejo que o prato é redondo e, dependendo da perspectiva adotada, vejo que ele parece oval ou oblongo. $\mathrm{O}$ prato ter uma aparência oval na perspectiva $\mathrm{x}$ ou oblongo na perspectiva y é uma propriedade objetiva da relação entre o arranjo óptico do agente sensório-motor e o objeto, de modo que a explicação do fenômeno visual aqui esboçada não é necessariamente dependente de nenhum apelo a estados internos ou conteúdo representacional. Essa explicação dá conta da experiência visual de objetos em sua totalidade a partir de facetas dos mesmos, mas e a continuidade da experiência visual? É possível uma resposta similar. Primeiro, a percepção visual é um processo que se dá ao longo do tempo; segundo, o agente tem certa autonomia acerca do modo a partir do qual o estímulo visual é apreciado. Com o passar do tempo, o agente compreende os efeitos das suas ações para o fluxo de aparências. O enativismo sensório-motor, ao se interessar por essas questões, é geralmente apresentado como uma maneira de explicar o carácter intencional e fenomenológico da experiência perceptual. Ao contrário do que fazem enativistas autopoiéticos, ao buscar explicar uma variedade de capacidades cognitivas utilizando conceitos tais quais autonomia autopoiética e o dinamismo que 
ela acarreta, a abordagem sensório-motora geralmente trata do tema mais específico da experiência perceptual. Ele é tratado a partir da relação entre percepção e ação, entendida como uma relação dinâmica e constitutiva. De modo não trivial, perceber é agir, exercer certas capacidades sensório-motoras num ambiente onde há algo a ser percebido. Desse modo, usualmente enativistas sensório-motores se mantém neutros acerca de afirmações epistêmicas e metafísicas mais robustas, como a continuidade forte entre vida e cognição e uma suposta dependência metafísica das qualidades percebidas para com o organismo que as percebe (ambas mais facilmente endossadas por enativistas autopoiéticos). O destaque é a dimensão ativa da experiência:

Experiência visual é um modo de atividade envolvendo conhecimento prático sobre os padrões atualmente possíveis de comportamento e consequências sensórias associadas. Experiência visual se baseia em saber fazer, na posse de habilidades. ${ }^{13}$

Uma questão a ser discutida é o quão longe vai o enativismo sensório-motor: tudo se reduziria ao exercício de habilidades sensório-motoras? O enativista que concorda com a afirmação acima precisa afirmar que atitudes proposicionais se reduzem ao exercício de habilidades sensório-motoras? Não viria essa proposta forçosamente rejeitar distinções como aquela entre conhecimento proposicional e conhecimento prático? Precisaríamos reconceber as noções teóricas como derivativas os dependentes do conhecimento prático entendido enquanto habilidade sensório-motora? Com relação a esses questionamentos poderíamos buscar entender como noções semânticas (representação, conteúdo, significado) podem ser naturalizadas de modo a serem explicadas como emergindo de padrões sensório-motor. REC oferece esse tipo de resposta.

\subsection{Enativismo Radical ou REC}

É possível distinguir entre variedades do enativismo que rejeitam a ubiquidade de intencionalidade dotada de conteúdo representacional (radicais) e variedades que revisam a noção de representação de modo a compati-

\footnotetext{
${ }^{13}$ Visual experience is a mode of activity involving practical knowledge about currently possible behaviours and associated sensory consequences. Visual experience rests on know-how, the possession of skills J. K. O'regan Alva Noë. "A Sensorimotor Account of Vision and Visual Consciousness", 2001, p. 946. Tradução minha.
} 
bilizá-la com explicação do cognitivo centradas na ação (conservadoras) ${ }^{14}$. Portanto, as estratégias radicais mantêm o ímpeto original anti-representacionalista, cujo objetivo era ser um antídoto às abordagens que centralizavam a noção representação na explicação dos processos cognitivos. Como é afirmado: "O único bom enativismo é um enativismo propriamente radical"15 Não se trata de um anti-representacionalismo que se poderia dizer metafísico, mas sim epistemológico, como princípio metodológico busca-se minimizar o papel explicativo da noção de conteúdo representacional, sem presumir previamente uma ontologia da cognição. A abordagem que reivindica alcunha de radical ou REC é aquela defendida por Daniel Hutto e colaboradores (Cf. Hutto, 2015; Hutto \& Satne, 2015; Hutto \& Myin, 2013 \& 2017). Ela ocupa-se principalmente da tarefa de identificar dificuldades que qualquer teoria que pretenda valer-se de uma noção naturalizada de conteúdo semântico para explicar as capacidades perceptual e motora de organismos vivos e mostrar que essas dificuldades são insuperáveis. Os RECers traçam uma divisão entre cognição básica e cognição superior, a última aludindo a faculdades cognitivas intuitivamente mais complexas - como aquelas para formação de atitudes proposicionais, tomadas de decisão, álgebra, do que percepção e movimento corporal.

A sugestão interpretativa desse artigo é que o enativismo autoproclamado radical deve ser entendido como um projeto que visa unificar o conjunto de alternativas anti-representacionalistas: teoria dos sistemas dinâmicos, ênfase em habibilidades e contingências sensório-motoras, robótica corporificada e a psicologia gibsoniana. A crítica ao enativismo autopoiético e sensório-motor é que ambos, ao fim e ao cabo, se comprometem com teses representacionalistas que a princípio visavam rejeitar. O problema filosófico diretamente enfrentando pode ser resumido nas seguintes perguntas: a representação é a marca do mental? Os estados mentais humanos são necessariamente representacionais? A resposta a ambas as questões é negativa. A ideia de "radicalidade" é oriunda do diagnóstico ${ }^{16}$ que as variedades al-

\footnotetext{
${ }^{14}$ Para uma exposição mais detalhada da distinção entre enativismo radical e conservador ver Hutto (2005).

15 The only good enactivism is a properly radical enactivism." Daniel D. Hutto e Erik Myin, Radicalizing Enactivism, 2013, p. 5. Tradução minha.

${ }^{16}$ Sob o qual não avaliamos o mérito aqui.
} 
ternativas não rejeitam de modo satisfatório uma leitura não representacionista de seus resultados. A perspectiva sensório-motor, sob certa interpretação, pode ser entendida como afirmando que nossos estados representacionais são corpóreos ou altamente informados por nossas disposições corporais. O enativismo autopoiético, por sua vez, é criticado na medida em que pode ser entendido como dependente de uma teoria naturalizada do conteúdo intencional, a ideia de uma intencionalidade sem conteúdo, de uma diretriz ou telos que explica a cognição de organismos simples sem atribuir estados representacionais, deve ser desenvolvida. Alguém poderia afirmar que em sua atividade por busca de sentido a bactéria representa o ambiente ao qual se aproxima como rico em sacarose. $\mathrm{O}$ intuito de REC é "radicalizar versões existentes do enativismo e propostas explanatórias relacionadas através de um processo de clarificação conceitual" ${ }^{17}$. O objetivo é tornar o enativismo incompatível com essas leituras ao explicitamente rejeitá-las, com isso se rejeita de modo explícito e sem espaço para ambiguidades a tese de que a representação é a marca do mental.

A proposta radical de Hutto e colaboradores busca analisar a cognição humana em termos da interação entre o sistema autônomo dinâmico do qual o agente cognitivo faz parte enquanto entidade biológica com capacidades sensório-motoras, explorado nas formas de enativismo tratadas anteriormente, e o sistema dinâmico do qual faz parte enquanto organismo num ambiente social. A partir dessa interação seria possível explicar como a cognição superior emerge a partir da cognição básica. No que se segue prosseguimos com uma exposição do enativismo radical e avançamos ao expor sua proposta de tratamento do fenômeno denominado cognição superior.

\section{REC e Cognição Superior}

Antes de avançar, contudo, uma breve caracterização de representação e intencionalidade é relevante à subsequente discussão. Existem fenômenos paradigmaticamente cognitivos sobre os quais é comum a atribuição do que poderia ser denominado condições de correção (adequação, verossi-

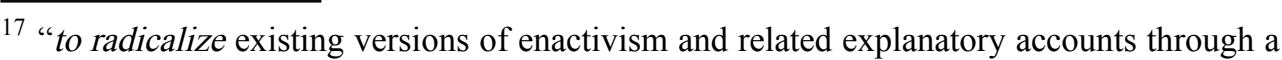
process of philosophical clarification." Daniel D. Hutto, "REC: Revolution Effect by Clarification", 2017, p.379. Tradução minha.
} 
milhança, corretude, etc). A imaginação, memória imagética e o pensamento abstrato são fenômenos mentais paradigmaticamente representacionais. Um estado é representacional quando "está por algo" e com relação a esse algo pode-se julgar, por exemplo, se de fato está por esse algo (é verdadeiro). Representações podem ser compreendidas como estruturas semânticas com condições mínimas de acurácia. A intencionalidade é em geral entendida de maneira associada. O que seria característico da intencionalidade é que seus objetos, aquilo ao que me direciono (sobre o que penso, imagino, etc.), podem ser não satisfeitos, serem inadequados, até mesmo inexistentes. Os itens intencionais, por assim dizer, são representados.

RECers afirmam que nem todas as formas de cognição envolvem conteúdo; se as aparências não nos enganam algumas cognições envolvem conteúdo; e que é possível (em princípio) explicar a cognição de modo cientificamente respeitável e sem lacunas ${ }^{18}$. Desse modo, o enativista radical deve, nos contextos descritos por ele como não representacional, empregar uma noção distinta de intencionalidade desprovida de conteúdo representacional, as vezes denominada Ur-intencionalidade, explicada em termos do acoplamento entre indivíduo e ambiente. Para compreender as origens da cognição com conteúdo deve-se explicá-la sem lacunas, ou seja, explicando uma continuidade entre cognição superior e cognição básica; isso é feito pelos autores reportando-se ao ambiente sociocultural. O exercer de certas habilidades específicas direcionadas a certas possibilidades de ação no ambiente durante grandes períodos de tempo que vão além do tempo de vida de um organismo é um modo de entender essa intencionalidade primitiva. Assim como a cognição não representacional é relacionada a essa intencionalidade. No exemplo de um sapo que rastreia os movimentos de uma mosca: o sapo vê a mosca se, e somente se, ele está engajado em atividades específicas num ambiente no qual há moscas a serem vistas; de fato, só possível ver moscas em tais ambientes. Estar engajado em atividades específicas, por sua vez, envolve exercer uma série de habilidades herdadas de gerações passadas e adquiridas no trato com o ambiente. É importante uma clareza mínima acerca da noção de representação e de noções relacionadas, pois adota-se uma distinção entre cognição básica e superior onde a marca

${ }^{18}$ (Cf. Hutto \& Myin, 2017, p.165) 
distintiva da cognição superior é ser representacional. Assumindo uma teoria não representacionalista da cognição, surge o problema de enquadrar casos paradigmáticos de cognição humana que a princípio são casos paradigmáticos de representação.

Pode inserir-se os casos de cognição superior no modelo explicativo das estratégias enativistas mais radicalizadas, como já mencionamos, de duas maneiras, um eliminativismo metodológico ou a de perspectiva emergente. É possível contestar a necessidade de conteúdo representacional (marca do superior) para compreender certos casos de cognição, sendo, portanto, eliminativista. Também é possível explicar como a partir da cognição básica surge, sob certas condições, cognição com conteúdo representacional, sendo, portanto, emergente. A seguir explora-se a segunda sugestão, que não promove um eliminativismo global. Enquanto proposta naturalista, para compreender as origens da cognição com conteúdo deve-se explicá-la sem lacunas, ou seja, explicando uma continuidade entre cognição superior e cognição básica; isso é feito pelos autores reportando-se ao ambiente sociocultural. Contudo, antes de mais nada, é preciso avaliar como RECers compreendem a cognição básica a partir da sua relação com o ambiente em sentido ecológico.

REC explica as capacidades cognitivas em geral a partir da ênfase em seu caráter corporificado e do seu desenvolvimento ao longo de períodos consideráveis de tempo. Nesse sentido, explicam as capacidades cognitivas em termos de um acoplamento dinâmico com o ambiente. Primeiro, todas as formas de cognição são corporificadas, consistem de "concretos padrões de interação dinâmicos espaço-temporalmente estendidos entre organismos e o seu ambiente. ${ }^{.19} \mathrm{O}$ principal exemplo de padrão dinâmico de interação ou acoplamento entre ambiente e organismo utilizado é aquele encontrado na percepção através das assim chamadas contingências sensório-motoras, tratadas acima. As interações dinâmicas, por sua vez, devem ser entendidas como "ancoradas no, moldadas por e explicadas por, e explicadas por nada mais que, o histórico das interações prévias do organismo." ${ }^{20}$ Destaca-se que a história do organismo deve ser entendida como incluindo o desenvolvi19 "concrete spatio-temporally extended patterns of dynamic interaction between organisms and their environment" Daniel D. Hutto e Erik Myin, Radicalizing Enactivism, 2013, p. 3. Tradução minha. 
mento ontogenético e filogenético. Consequentemente, para explicar as capacidades cognitivas do agente cognitivo particular é inadequado reportar-se somente ao desenvolvimento dele, sendo necessário considerar fatores como a seleção natural. Um exemplo de explicação pode ser dado pensando-se no caso de um sapo e sua habilidade de capturar moscas. Um sapo pode rastrear os movimentos de uma mosca e capturá-la graças a uma série de habilidades herdadas (características filogenéticas do sapo) e adquiridas (características ontogenéticas do sapo), mesmo que não tenha estados representacionais (o que é extremamente plausível). A atividade cognitiva de captura de moscas (rastreá-las ao dar-se ênfase à experiência visual) pode ser entendida de maneira naturalizada em termos do histórico a partir do qual as habilidades filogenéticas e ontogenéticas se desenvolveram. A ação do sapo é orientada à captura da mosca devido a desenvolvimentos evolutivos ao longo de um período extenso de tempo. Contudo, é preciso enfatizar que para o enativista radical até mesmo as capacidades cognitivas mais básicas possuem um elemento de aprendizagem. Todas as interações são possíveis graças a interações prévias entre o organismo e o ambiente que moldam como serão as interações futuras.

A seleção natural faz com que o sapo seja capaz de interagir com o ambiente eficientemente em termos de sucesso reprodutivo e explica a cognição requerida para captura da mosca. Na interação malsucedida com o ambiente, a atividade específica que caracteriza um estado cognitivo não foi performada, logo, não se trata de uma ocorrência daquele estado cognitivo. A normatividade a partir de REC deve ser assim compreendida: ao menos nos casos da cognição básica, não realizar as atividades (especificadas) relevantes é não alcançar os estados cognitivos relevantes. A consequência é um certo disjuntivismo acerca da percepção: o que coloquialmente caracterizamos como erro perceptual não é considerado nessa perspectiva como um caso legítimo de percepção. O "erro perceptual” não é propriamente uma instância particular de percepção. A ideia de uma intencionalidade primitiva desprovida de conteúdo é a ideia de uma orientação ou direção ${ }^{21}$ com relação

\footnotetext{
20 "grounded in, shaped by, and explained by, and explained by nothing more, or other, than the history of an organism's previous interactions" Daniel D. Hutto e Erik Myin, Radicalizing Enactivism, 2013, p. 8. Tradução minha.

${ }^{21}$ Um termo utilizado na literatura consultada de língua inglesa é directness.
} 
a atividades específicas (cognitivas) moldada pelo histórico de interações com o ambiente que é falível e nem por isso representacional. Ela é falível dada a contingência de ter sido selecionado a partir de um histórico contingente de encontros com o ambiente no qual as estruturas que geraram maior sucesso reprodutivo permaneceram, não por seu objeto ser um estado mental interno.

A ideia dessa intencionalidade desprovida de conteúdo pode ser empregada para explicar a cognição com conteúdo como emergindo da mesma. Ao desassociar conteúdo de intencionalidade, podemos explicar a cognição com conteúdo (e intencionalidade no sentido mais tradicional) em termos do tipo de habilidade (e consequentemente ambiente) nos quais se dá esse tipo de cognição. A sugestão de Hutto \& Myin (2017) é que "Somente mentes que dominaram um tipo especializado de prática sócio-cultural podem se engajar em cognição que envolve conteúdo.”"22 Em linhas muito gerais, seres humanos em processos como a experiência visual são mentes básicas, assim como o sapo no exemplo acima é uma mente básica. Dado o nosso histórico de interações com ambiente que desenvolvemos interações especializadas que conteúdo representacional. Hutto \& Myin (2017) não avançam exaustivamente acerca do que seriam nichos socioculturais ou tipos especializados de prática socioculturais pelo se presume ser duas razões principais. Primeiro, os autores dedicam-se às objeções a REC já presentes na literatura, como a crítica de que a descontinuidade psicológica da proposta implica uma descontinuidade evolutiva que inviabiliza REC. Segundo, os pormenores da proposta deveriam ser articulados pelas Ciências Cognitivas, não a partir da Filosofia das Ciências Cognitivas, mais voltada à tarefa de clarificação conceitual.

\section{Considerações Finais}

Apesar de não avançar de maneira significativa a proposta é claro o modo como devem se dar os avanços na agenda radical. Como adota-se uma forma menos rígida de naturalismo, um naturalismo metodológico, o fenô-

\footnotetext{
22 "Only minds that have mastered a certain, specialized kind of sociocultural practice can engage in content-involving cognition." Daniel D. Hutto e Erik Myin, Evolving Enactivism, 2017, p. 177. Tradução minha.
} 
meno do conteúdo representacional e da intencionalidade pode ser explicada por diversas fontes reputadas de conhecimento científico, não se limitando à Física e à Química; de modo a empregar "os achados de uma variedade de ciências que incluem não somente as exatas, mas também arqueologia cognitiva, antropologia, psicologia do desenvolvimento, e assim por diante." ${ }^{23}$ Com isso diversas possibilidades de desenvolvimento e articulação da proposta se encontram disponíveis. Uma maneira plausível de compreender e explorar a condição de estar engajado em "tipos especializado de práticas socioculturais" é através do estudo acerca da habilidade de realizar ações em conjunto. Rolla (2018) desenvolve essa hipótese a partir dos trabalhos de Gallagher (2008) e Gallagher \& Varga (2014), buscando avançar a agenda radical a partir de uma leitura dos resultados acerca de neurônios espelho. A partir disso poder-se-ia explicar como percebemos os estados mentais de outros diretamente, isto é, de modo não representacional. No espírito de retificar perspectivas enativistas ou amigáveis ao enativismo poder-se-ia também investigar as atividades socioculturais especializadas a partir das contribuições já presentes no enativismo sobre o tópico da cognição social. Tendo delineado a proposta enativista radical aos casos de cognição superior e indicado as possibilidades de avanço dessa agenda, torna-se claro o carácter frutífero da proposta e como essa proposta se insere numa tradição de quase 30 anos cujo potencial continua não esgotado. Como afirma Ramsey (2017) utilizar conteúdo representacional como critério para de demarcação do metal artificialmente restringe a investigação do fenômeno cognitivo, além de incorrer em uma petição de princípio. De tal modo, dado esse panorama e exposição, pode-se afirmar que ser radical não é de modo algum irrazoável. Contra a proposta de Hutto e Myin podemos destacar duas dificuldades. Primeiro, ela deixa em aberto como habilidades cognitivas básicas se relacionam com habilidades sócio-culturais. De certa maneira, trata-as como uma coincidência evolutiva fortuita. Eles afirmam dar uma abordagem naturalista completa e sem lacunas da cognição, mas como reconhecido pelos autores e apontado por Moyal-Sharrock (2019), demanda uma torção ou dobra (kink) em nossa compreensão da cognição. Mentes superiores são distinguíveis de

23 "the findings of a wide variety of sciences that include not just the hard sciences but also cognitive archeology, anthropology, developmental psychology, and so on." Daniel D. Hutto e Erik Myin, Evolving Enactivism, 2017, p.168-9. Tradução minha. 
demais mentes encontradas na natureza. Cognição representacional que envolve conteúdo é biologicamente contínua com outras formas de cognição, mas funcionalmente distinta, apresenta uma drástica curva na continuidade evolutiva entre as mais diversas complexidades comportamentais encontradas nos sistemas cognitivos. Contudo, a partir do momento em que é possível vincular os comportamentos complexos característicos do que vinha sendo chamado de cognição básica com os comportamentos complexos do que vinha sendo chamado cognição superior, perde-se umas das principais motivações para uma ênfase nessa distinção. Desse modo, mesmo a perspectiva radical, ao se comprometer com uma marca da cognição superior (a representação) de certo modo muda o escopo dos problemas com a noção de representação para um subconjunto de casos. Fica em aberto se, limitado a esse subconjunto, esses problemas são tratáveis.

\section{Referências}

GALLAGHER, S. "Understanding Others: Embodied Social Cognition”. In Handbook of Cognitive Science: An Embodied Approach Calvo, P. and Gomila, T. (eds.) (2008), pp. 439-52.

GALlaGHER, S., SOMOGY, V. "Social Constraints on the Direct Perception of Emotions and Intentions." Topoi, no. 33: 195-99, 2014.

GIBSON, J. J. The Ecological Approach to Visual Perception. New York: Psychology Press. 2015.

DE JAEGHER, H. \& DI PAOLO, E. "Participatory sense-making: An enactive approach to social cognition". Phenomenology and the Cognitive Sciences 6(4), pp. 485-507, 2007.

DENNETT, D. Consciousness Explained. Boston: Little, Brown. 1991.

DI PAOLO, E., CUFFARI, E. C., \& JAEGHER, H. D. Linguistic Bodies: the Continuity between Life and Language. Cambridge: MA: The MIT Press. 2018

HUFFERMANN, J. D. \& NOGUEZ, P. M. R. "Propostas Enativas e a questão da continuidade entre formas de cognição". Prometheus 33. Dossiê Linguagem e Cognição. 2020. E-ISSN: 2176-5960

HURLEY, S. "Perception and Action: Alternative Views." Synthese 129, pp. 3-40, 2001. 
HUTTO, D. "REC: Revolution Effect by Clarification". Topoi 36(3), pp. 457-472, 2017.

HUTTO, D. D., MYIN, E. Evolving Enactivism: Basic Minds Meet Content. Cambridge, Massachusetts: The MIT Press. 2017.

HUTTO, D. D., MYIN, E. Radicalizing Enactivism: Basic Minds without Content. Cambridge, Massachusetts: MIT Press. 2013.

HUTTO, D. D., SATNE, G. "The Natural Origins of Content." Philosophia 43 (3), pp. 521-36, 2015

HUTTO, D.D. 2005. "Knowing What?: Radical versus Conservative Enactivism". Phenomenology and the Cognitive Sciences 4: 389-405.

KIVERSTEIN, J. \& RIETVELD. E. "Reconceiving representation-hungry cognition: an ecological-enactive proposal". Adaptive Behavior. Online first, 2018, p. 1-17.

MATURANA, H.R. \& VARELA, F.J. Autopoiesis and cognition: the realization of the living. Kluwer, Dordrecht. 1980.

MERLEAU-PONTY, Maurice. Fenomenologia da Percepção. Trad. Carlos Alberto Ribeiro de Moura. São Paulo: M. Fontes. 1994.

MILlIKAN, R. White Queen Psychology and Other Essays for Alice. Cambridge: MIT Press, 1993.

MOYAL-SHARROCK, D. "From deed to word: gapless and kink-free enactivism”. Synthese. (2019) DOI: 10.1007/s11229-019-0218-5

NOË, A. Action in perception. MIT Press, Cambridge MA, 2004.

NOË, A. Varieties of presence. Harvard University Press, Cambridge, MA, 2012.

RAMSEY, W. “Must Cognition be Representational?”. Synthese, vol. 194, n. 11, p. 4197-4214, 2017 (2015).

ROLLA, G. "Enativismo Radical: Exposição, Desafios e Perspectivas" In Princípios: Revista de Filosofia. Natal, v. 25, n. 46, jan.-abr.2018

ROLLA, G. "Radically Enactive High Cognition" Disponível no academia.edu do autor Dissertatio, [s. 1.], v. 47, p. 26-41, 2018.

O'REGAN, J. K. \& NOË, A. 2001. "A Sensorimotor Account of Vision and Visual Consciousness". Behavioural and Brain Sciences 24: 939-1031. 
Perspectiva Filosófica, vol. 46, n. 2, 2019

TURVEY, M. T., SHAW, R. E., REED, E. S., \& MACE, W. M. "Ecological laws of perceiving and acting: In reply to Fodor \& Pylyshyn". Cognition, 9, 237-304. 1981.

VARELA, F.J, THOMPSON, E., ROSCH, E. The Embodied Mind. Cambridge, Massachusetts: MIT Press. 1991.

WARD, D. \& SILVERMAN, D. \& VILLALOBOS, M. "Introduction: The Varieties of Enactivism”. Topoi 36(3), 2017, pp. 365-375. 